\title{
LAS ESCULTURAS ENCARGADAS POR CARLOS V A LEONE LEONI EN 1549 Y SU ACABADO EN ESPAÑA POR POMPEO LEONI
}

\author{
Luis ArCiniega García \\ Universitat de València
}

En Bruselas en 1549 Carlos V encargó al escultor Leone Leoni cuatro bronces y cuatro mármoles, a los que se añadieron nuevos encargos. Trabajados en Milán, los primeros, junto a otras obras, llegaron a España con la venida del emperador y la corte. En este artículo se analiza el devenir de los mármoles y un busto (Museo del Prado, E-260, E-262, E-267, E-269, E-291), que se enviaron desde Génova a Cartagena, donde permanecieron hasta 1568. Después de años de olvido Pompeo Leoni fue encargado de concertar su traslado hasta su casa en Madrid con Juan de Lugano, artista y empresario del mármol. Pompeo finalizó la mayoría de estas obras.

Palabras clave: Escultura; Renacimiento; Retrato de corte; Mármol de Carrara; Transporte; Bruselas; Milán; Génova; Cartagena; Madrid; Leone Leoni; Pompeo Leoni; Juan de Lugano.

\section{THE SCULPTURES COMMISSIONED BY CHARLES V FROM LEONE LEONI IN 1549 AND COMPLETED IN SPAIN BY POMPEO LEONI}

In Brussels in 1549 Charles V commissioned four bronze and four marble sculptures from Leone Leoni, to which were added new orders. The sculptor worked on them, especially the bronzes, in Milan, and they were shipped to Spain along with other works at the time of the arrival of the Emperor and the Court. This article discusses the history and evolution of the marbles and a bust (Prado Museum: E-260, E-262, E-267, E-269, E-291), which were sent from Genoa to Cartagena, where they remained until 1568. After years of neglect, Pompeo Leoni was commissioned to arrange for their transfer to his house in Madrid along with Juan de Lugano, artist and dealer in marbles, where Pompeo finished most of these works.

Key words: Sculpture; Renaissance; Portrait; Carrara marble; Transportation; Brussels; Milan; Genoa; Cartagena; Madrid; Leone Leoni; Pompeo Leoni; Juan de Lugano.

Giorgio Vasari en la biografía que dedicó al escultor Leone Leoni, destacó las muchas mercedes que le concedió el emperador, como dinero, aposentos en el mismo palacio de Bruselas para poder visitarlo mientras trabajaba, una casa en Milán, el título de caballero y privilegios de nobleza para él y sus descendientes..., y alabó muchas de sus obras realizadas antes de 1567, como las medallas y las esculturas en mármol y en bronce. Mientras que de su hijo Pompeo decía escuetamente, lo que es comprensible por la distancia, que estaba al servicio del rey de España, 
que deseaba volver a Milán, y que estaba a la altura de su padre ${ }^{1}$. Ya desde tierras hispanas Diego de Villalta que hacia 1590 visitó el taller de Pompeo y reprodujo gráficamente muchas de las obras almacenadas y custodiadas, calificó a padre e hijo de excelentes scultores y statuarios de nuestro tiempo ${ }^{2}$, y a comienzos del siglo XVII, fray José de Sigüenza, cronista jerónimo y del monasterio de El Escorial, destacó a los Leoni como artífices de mucho nombre, grandes responsables de la labor escultórica en bronce de la basílica, y en concreto Pompeo como un artista muy agasajado por Felipe $\mathrm{II}^{3}$; y Luis Cabrera de Córdoba, cronista del monarca, al enumerar las virtudes de éste destacó su protección y familiaridad con los artistas, y entre los escultores dijo de Pompeo Leoni, milanés, y Juan Bautista Monegro, toledano, que eran estimados porque hazian estatuas que enbiaban al que las miraba muda voz, ciega vista, sangre fria, aquel de bronze, de marmor $e^{4} e^{4}$. Indudablemente Pompeo Leoni, que había fallecido en la década anterior a la publicación de estas palabras, alcanzó en la corte española un gran prestigio como escultor, y en particular como broncista, que culminó con su trabajo para la basílica de El Escorial: junto a su padre en Milán realizó los elementos de bronce de las arquitecturas del retablo mayor, custodia y cenotafios, así como las estatuas de bronce para los dos primeros; y ya fallecido Leone Leoni, junto a Jacopo da Trezzo y en España realizó las diez figuras de los grupos sepulcrales y los escudos de los cenotafios de Carlos V y Felipe II.

Leone Leoni (Arezzo, 1509 - Milán, 1590), que de 1549 a 1555 realizó importantes encargos, entre otros, para la reina María de Hungría y Carlos V, de quien fue nombrado escultor cesáreo, fue instado en 1556 a trasladarse con la corte a España. Finalmente, consiguió evitar su salida de Italia y envió a su hijo Pompeo (h. 1533 -Madrid, 1608), quien cumplió con las expectativas y ocupó el puesto de escultor de S. M. hasta el final de sus días. En este tiempo permaneció en España, a excepción de su estancia en Milán entre 1582 y 1589 para trabajar con su padre los elementos arquitectónicos y escultóricos de bronce del retablo mayor y custodia de la basílica del Escorial, así como los arquitectónicos en bronce de los cenotafios, y en 1594 para finalizar el grupo escultórico de bronce de Ferrante Gonzaga.

La documentación inédita que presentamos hace referencia precisamente a los encargos realizados por Carlos $\mathrm{V}$ a Leone Leoni en 1549, y el difícil devenir de esas obras, almacenadas durante décadas, lo que muestra elocuentemente la variabilidad de funciones de las obras escultóricas y permite reflexionar sobre sus usos e intenciones ${ }^{5}$.

A partir de una carta escrita en 1553 por Ferrante Gonzaga, gobernador de Milán, al emperador $^{6}$ se puede establecer que el encargo consistía en cuatro esculturas de bronce y cuatro de mármol, pero que se habían añadido muchas otras, como veremos, por iniciativa del escultor, del emperador y de otros allegados. Respecto a las de mármol, el documento que presentamos confirma claramente su temática. Así, por carta de Alberto Clavijo, deán de Cartagena, sabemos que el emperador ordenó a Leone Leoni que debía enviar el embajador de Génova hasta el puerto de la citada ciudad española las esculturas de mármol encargadas en 1549. El 31 de enero de 1556 desde Amberes el emperador se lo comunicó al deán mediante carta que recibió el 25 de abril, pidiéndole que le avisara a la llegada de las mismas, y el embajador le advirtió que se enviaban en la carraca Centuriona con la documentación pertinente; el 1 de mayo el deán de Cartagena comunicó la lle-

\footnotetext{
${ }^{1}$ VASARI, 1568: secondo volumen della Terza Parte, 841-842.

2 Diego de Villalta, Tratado de las estatuas antiguas (h. 1590) en SAnChez Cantón, 1923: vol. I, pp. 283-304.

${ }^{3}$ SigÜEnZA, 1605: Parte segunda, discursos XIV y XXI.

${ }^{4}$ Cabrera de Córdoba, 1619: 925.

${ }^{5}$ Este artículo se inscribe dentro del proyecto I+D «Memoria y significado: uso y recepción de los vestigios del pasado» (HAR 2009-13209), subvencionado por el Ministerio de Economía y Competitividad.

${ }^{6}$ Carta de Ferrante de Gonzaga al emperador (28-12-1553). Citada por M. Pedro de Madrazo en L'Art, junio 1877, enero 1878. PLON, 1887: 95-97 y 368-369.
} 
gada en buenas condiciones de las estatuas de mármol en cuatro cajas de madera y fuera de ellas un busto desbastado (desgrosado), lo que coincidía con el listado facilitado; tras la verificación se volvieron a clavar las cajas como venían y el deán las puso bajo llave en una estancia baja en la casa real que su tío y predecesor en el cargo hizo para el servicio de S. M. ${ }^{7}$ Cartagena, por su condición de importante y transitado puerto, y con buena comunicación terrestre con Castilla, se convirtió en destino habitual de las piezas artísticas procedentes principalmente de Italia. La construcción de una casa real que se usó como depósito de las piezas indica claramente el tránsito de enseres.

A través de la documentación publicada, principalmente por A. Ronchini y E. Plon en el siglo XIX, podemos ubicar este conocido encargo en los inicios de la vinculación de los Leoni a la casa de Austria ${ }^{8}$. Los primeros pasos de Leone Leoni cuentan con la protección de Pietro Aretino, y su labor desde 1536 se centra en las medallas y en diferentes cecas, como Ferrara y Roma. Aquí, en marzo de 1540 fue condenado a galeras por su ataque al joyero papal. Un año más tarde, el príncipe Andrea Doria, almirante de la flota imperial, consiguió su libertad. Como correspondencia quedó a su servicio realizando medallas y plaquetas de bronce laudatorias de su protector bajo erudita impronta clásica. Evidentemente, Leone Leoni quedaba bajo la esfera imperial y los encargos se sucedieron. Alfonso de Avalos, marqués del Vasto y gobernador del estado de Milán, invitó al escultor en nombre del emperador en 1541. Ese mismo año el senado milanés le pidió cuatro medallas conmemorativas de la entrada del emperador; un año más tarde fue nombrado maestro grabador de la ceca de Milán, cuyo cargo ocupó hasta 1545; en 1543 obtuvo en exclusiva los derechos para hacer las medallas con los retratos del emperador; éste, le encargó una medalla en honor a la emperatriz Isabel, fallecida en 1539, por lo que marchó a Venecia en 1544, como supuso E. Plon, para utilizar como modelo el retrato realizado por Tiziano y enviado al emperador a Bruselas ese mismo año y del que no se separó hasta el final de sus días'; en 1546 fue nombrado maestro general de la ceca de Parma y Piacenza, y llamado por la viuda del marqués de Vasto para que realizara una máscara de su marido que pudiera utilizarse en un proyecto escultórico. En 1546 la llegada de Ferrante Gonzaga como nuevo gobernador de Milán supuso el impulso definitivo hacia el desarrollo de su actividad medallística y la escultórica en mármol y bronce en la corte imperial. De hecho, ese mismo año lo llamó a su servicio y le concedió la casa que fue germen de lo que sería su palacio y taller: la casa degli Omenoni en Milán. Desde ella participó en la renovación de las residencias del gobernador y en la exaltación de los Habsburgo, por ejemplo, con la propuesta en 1547 de hacer una escultura ecuestre de Carlos V, nunca llevada a cabo, y con su participación en la entrada en Milán del príncipe Felipe en diciembre de 1548, para quien el propio Leoni meses antes elaboró como regalo de la comunidad de Piacenza un relieve en plata de esta ciudadela. Finalmente, Leone Leoni recibió la invitación para ir a Bruselas a trabajar para los Habsburgo, lo que suponían dos importantes patronos: Carlos V y María de Hungría ${ }^{10}$; a los que se unía su influyente protector Antoine Perrenot de Granvelle, obispo de Arras. Leone partió con su hijo Pompeo en el séquito del príncipe Felipe, y llegaron a Bruselas el 21 de marzo de 1549.

En carta fechada en Bruselas el 30 de marzo dirigida por el escultor a Ferrante Gonzaga le comunica su encuentro con Carlos V, al que presentó a instancias de su protector y destinatario de la carta una medalla de oro del príncipe Felipe, que la tuvo en gran estima y por la que le recompensó con 200 escudos, y autorizó a que entregara otras a sus hermanas María de Hungría, gobernadora

\footnotetext{
${ }^{7}$ Archivo General de Simancas (AGS), Estado, legajo 113, f. 124

${ }^{8}$ Ronchini, 1865: vol. III, 9-41. Plon, 1887. En gran medida sobre la base documental del anterior, Proske, 1956. Mezzatesta, 1980. El más reciente estudio que incorpora los avances en HelmstutLer Di Dio, 2011.

${ }^{9}$ Finalmente se perdió en un incendio. El conservado de Tiziano y que se llevó a Yuste, hoy en el Museo del Prado, es algo posterior.

${ }^{10}$ Estella, 2000.
} 
de Flandes, y Leonor, viuda de Francisco I rey de Francia. Además, señala que el emperador le había mandado hacer un modelo de su estatua ecuestre que el mismo gobernador de Milán deseaba costear, y que le había encargado que hiciese rápidamente una medalla con su efigie y otra con la de la emperatriz, a partir de muchos retratos que le enseñó, así como dos estatuas de medio cuerpo de tamaño natural con los mismos personajes. Proyectos para los que le facilitó habitación en el mismo palacio, como ya indicó Giorgio Vasari ${ }^{11}$. En estos encargos es evidente el salto que de la medallística se hace a la escultura, y en ambas el interés de Carlos V por controlar la imagen imperial, pero también el uso afectivo de las obras, ocupando en este sentido un importante papel la memoria conjunta con su esposa. En octubre recibió una pensión anual de 150 escudos de oro, y en noviembre fue nombrado "cavaliere cesareo", con derecho a heredar el título. La relación de los Leoni con los Habsburgo se haría generacional merced a la interpretación fidedigna, decorosa, y de gravedad clásica, propia de la virtus romana, del arte escultórico que encabezaron desde mediados del siglo XVI a inicios del XVII ${ }^{12}$.

Leone Leoni recibió diversos encargos de María de Hungría, gobernadora de Países Bajos, como retratos familiares en mármol y bronce, que desde Milán se trasladaron a Bruselas en 1556 y finalmente a España en 1558: en bronce una estatua de cuerpo entero de la reina de Hungría y otra del príncipe Felipe, y un busto de mármol. Además, Leone presentó a la gobernadora un ambicioso proyecto para que una galería del palacio de Binche, a las afueras de Bruselas, evocase la antigüedad romana mediante bronces de copias de obras clásicas. Por esta razón en 1549 negoció la adquisición de los moldes realizados por Primaticcio para el rey Francisco I de Francia y arrinconados tras la muerte de éste en marzo de 1547. Finalmente, se enviaron en 1550, pero cuatro años más tarde los moldes fueron destruidos por las tropas francesas de Enrique II en su asalto al palacio. En este tiempo también se ofreció a Ferrante Gonzaga un proyecto de decoración para el palacio de la Gualteria, cerca de Milán ${ }^{13}$ y fueron frecuentes los contactos con el obispo de Arras.

Con la autorización de Carlos V, y con la exigencia de desempeñar su labor en la faceta de broncista para él y su hermana, en diciembre de 1549 Leone Leoni se trasladó a Milán, donde fijó su residencia cerca de la catedral en el céntrico barrio de Moroni, en la que sería conocida como Casa degli Omenoni, donde plasmó a través del edificio, principalmente hacia 1565, y las colecciones artísticas que contenía su formación, gustos y conocimientos clásicos, su posición como noble y artista en la corte de los Habsburgo y su relación con sus patrones; y cerca de la misma estableció su taller ${ }^{14}$. Su marcha a la capital lombarda, bajo poder imperial, se explica porque era uno de los principales centros de fundición y trabajo del metal de toda Europa. En ella volvió a ocupar el cargo de maestro grabador de la ceca al menos hasta 1571. Su prestigio atrajo numerosos encargos, que junto a la desvinculación del control directo del emperador hizo que éste sospechase

${ }^{11}$ Rochinn, 1865: 25-26. La lectura de la carta muestra que su presentación fue la medalla de oro del Príncipe para varios reales y familiares destinatarios, y no diferentes medallas familiares como gran parte de los historiadores han defendido desde Ronchini. Se despedía Leone prometiéndole al gobernador una medalla del príncipe y otras que debía hacer.

${ }^{12}$ Destacó su independencia de la línea manierista y de las libertades de Miguel Ángel (al que admiraba), y su relación con la estatuaria alemana renacentista CAMÓN, 1961: 369. Se ha señalado en Leone un naturalismo clasizante herencia de la escuela véneto-paduana CASTRILlon, 1968. Incidió en la impronta de la virtus romana MezzATesta, 1980.

${ }^{13}$ Basándose en Giorgio Vasari, RonchinI, 1865: 12-14 y 26-27. Broucher, 1981: 23-26. Del contacto de Leoni con Primaticcio tenemos constancia a través de las palabras de este último por cartas desde finales de octubre de 1549 hasta final de año, Lettere, 1977: 57-62.

${ }^{14}$ Fija su llegada el día 12 de diciembre (Plon, 1887: 57). Sobre la casa véase NebBia, 1963; Mezzatesta, 1980: $172-$ 242; Rossi, 1995: 21-30; Conti, 1995: 39-44; Helmstutler Di Dio, 2011: 107-131. Este trabajo se centra en el estatus del artista, que también ha sido destacado como un modelo de artista noble que se importará a tierras italianas en MARQUES, 2004: 95-97. 


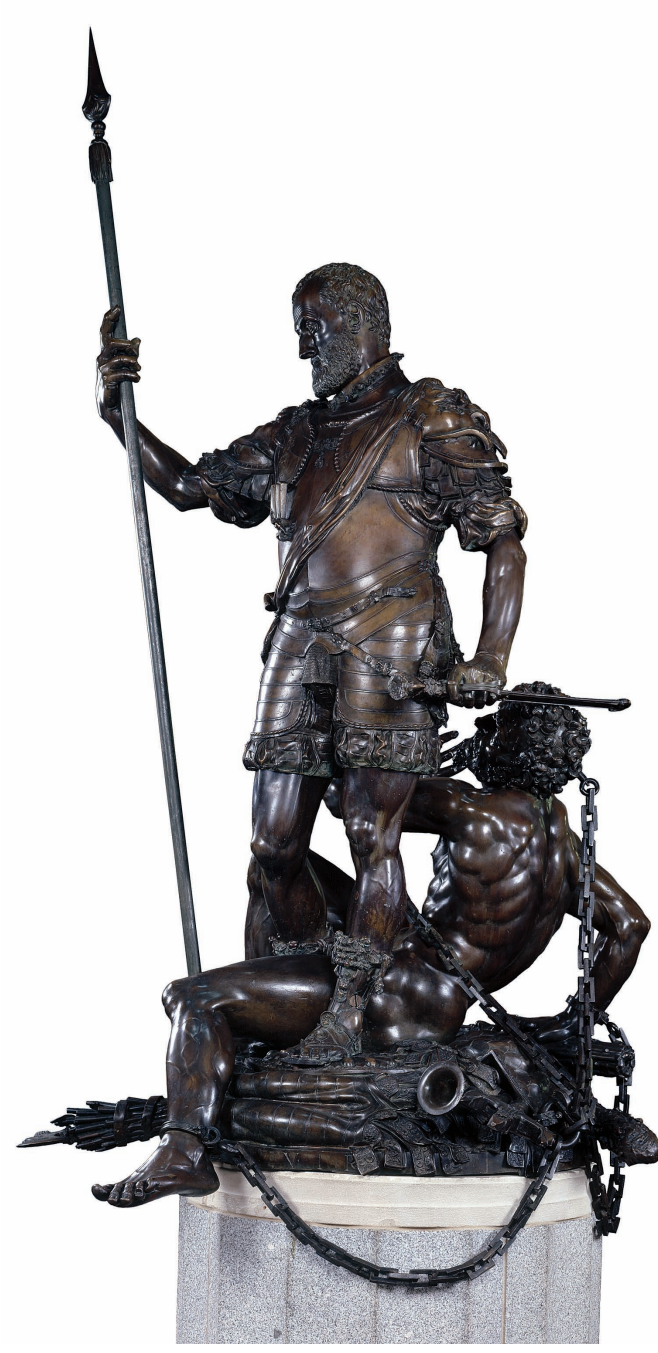

Fig. 1. Carlos V y el Furor. Leone Leoni, 1550-1553, y acabada por Pompeo Leoni en 1564 Fundido en bronce, $251 \mathrm{~cm}$ x $143 \mathrm{~cm}$ x $130 \mathrm{~cm}-825 \mathrm{~kg}$. (C) Museo del Prado, E-273.

que no avanzaba lo debido en sus encargos de obras de bronce y mármol. La gobernadora le reclamó, a través del obispo de Arras, las trazas de la galería que pretendía hacer y que le mostró en su cámara en compañía del mismo obispo para apreciar el efecto que en ella harían las esculturas de tamaño natural. La contestación del escultor en junio de 1550 no ofrecía lugar a dudas de la defensa de su arte: no tenía las trazas y no le servían, pues no le eran relevantes porque las estatuas no debían hacerse para la galería, sino la galería construirse para las estatuas de tamaño natural ${ }^{15}$.

En dos cartas que en 1550 envió Leone desde Milán al mismo destinatario hablaba de sus avances en los encargos realizados por el emperador en 1549 y que conocemos por documentos pos-

${ }^{15}$ Plon, 1887: 64-65 y 360. Además, decía quedaba a la espera de la leyenda y motivo para el reverso de las medallas. 
teriores, pero también de otras iniciativas. Por ejemplo, expuso que al ver una piedra sumamente preciosa se le ocurrió hacer un camée de la emperatriz destinado a S.M., muy precioso y de difícil ejecución. Era un cuadrado de dos brazas y media por cada lado, lo que descarta que se refiera a la escultura E-269 del Museo del Prado, aunque coincide con ésta en la utilización de ornamentos compartimentos, figuras, follaje, cornisas..., y que en palabras de Leone evidenciaba un "trabajo en el que estaba la vida de un hombre". También indicaba que había hecho moldes para tres esculturas de bronce que se preparaba a ejecutarlas, y que para la del emperador se le había ocurrido otorgarla más empaque añadiéndola la figura del Furor bajo sus pies, contraponiendo actitudes y gestualidad, con lo que conseguía una obra modesta y rara. También habló de la grata impresión que suscitó la estatua del príncipe. Y que, por propia iniciativa, al ver una piedra fantástica realizó un capricho que sería las más bella fantasía: por un lado grabado el emperador y su hijo, como fueron representados César y Augusto, y por el otro lado la emperatriz ${ }^{16}$. Il Primaticcio de paso por Milán visitó a Leone y en enero de 1551 comunicó a Granvelle su experiencia en el taller: vidi molte sue cose fatte eccellentemente, tutte ad onore della Cesarea Maestà, il quele messer Leone adora V. R. Sria come suo mecenate ${ }^{17}$.

En estas obras con conexiones constantes con la antigüedad domina el carácter dinástico y familiar de los encargos, así como el deseo de agasajar del artista. En este sentido, es evidente la implicación del artista en la configuración del programa de Carlos V y el Furor, cuyo retrato imperial era uno de los bronces encargados en 1549. A finales de 1550 ya hablaba de la inclusión del Furor para dotar a la escultura de varios significados ${ }^{18}$. En 1551 Leone propuso que la escultura de bronce tuviera armadura que pudiera desmontarse, ese año la fundió (como también la del príncipe), y el Furor en $1553^{19}$. Por lo tanto, se pasó de una escultura del emperador a un grupo alegórico, y con un tratamiento original, pues permite una representación del emperador desnudo como héroe clásico, y otra vestido con motivos decorativos de claras evocaciones guerreras del mundo antiguo. Además, la carga mitológica y alegórica, se acrecienta con la inclusión de la figura del Furor, que representa a todos los pueblos sometidos, y se inspira en los versos de Virgilio por los que Eneas inició la paz cuando encerró el Furor en el templo de Jano. Diego de Villalta, hacia 1590, al ver la obra en el taller de Pompeo, ofreció una rica descripción e interpretación. Además de admirar el artificio de la armadura desmontable, muestra las posibles lecturas que introduce la figura del Furor, que desde la antigüedad se representaba mediante un león en actitud indomable o un hombre bravo con espada en mano y antorcha encendida en otra. Para Villalta, el Furor puede entenderse como algo externo al vencedor, y por lo tanto hacer mención a los éxitos en el campo de batalla, como frente a Solimán, Barbarroja, Francisco I, los alemanes, los sajones...; pero también como algo interno, mediante el dominio de las pasiones, como en los últimos años de su vida mostró con su abdicación y retiro en Yuste ${ }^{20}$. Villalta presenta esta obra con una iconología abierta, muy probablemente con sugerencia de Pompeo como cicerone, y en este sentido bien pudiera incluir también una sutil referencia al propio artista, que se permitía un juego privado en situaciones de familiaridad como las vividas en el taller de Leone en Bruselas. Y es que la referencia que hace Villalta a la representación tradicional del Furor como un león, y la inclusión de esta idea en la transcripción del anónimo y largo poema de la Generación de la Guerra, permite inferir sobre el deseo de mostrarse ante el emperador con un carácter atemperado ante su señor, lo que suma una nueva lectura de dominio. De hecho, el artista usó la polisemia de su nombre en fechas cercanas a la realización del grupo; por ejemplo cuando ante la pérdida de confianza del emperador y la

\footnotetext{
${ }^{16}$ Plon, 1887: 62-63 y 69-71.

17 Lettere, 1977: 62.

${ }^{18}$ Edelstein, 2000: 37.

19 RochinNi, 1865: 16.

${ }^{20}$ Ha destacado estos aspectos MARíAs, 1995: 97-103.
} 
reina María de Hungría que condujo a la interrupción de su asignación. El obispo de Arras le aconsejó que trabajara en silencio, Leone contestó: ma e lioni non taciono nele grotte se non hano che manggiare ${ }^{21}$. Por otro lado, en esta obra de tanta implicación pudo el escultor incorporar su propio retrato, incluyendo una lectura más íntima de relación entre el imperial protector y el fiero artista. Los rasgos físicos del rostro, el cabello con mechones y la barba rala y pronunciada perilla, así como la presencia de la misma cadena resultan soluciones muy próximas al autorretrato que aparece en el reverso de la moneda dedicada a Andrea Doria (Museo del Prado O-982) (fig. 2), en este caso en recuerdo a su paso por galeras, pero también por su unión a tan importante protector. Cierto es que la expresión del Furor aparece deformada, pero esto es un recurso de alarde habitual entre los artistas de la época (fig. 3).

El encargo del emperador estaba sujeto a muchas distracciones, como el entusiasmo del

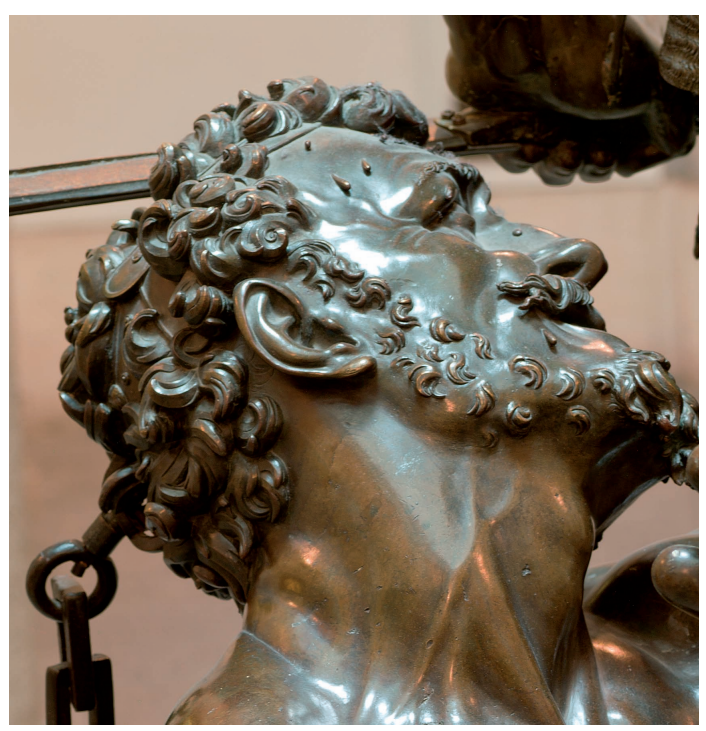

Fig. 3. Detalle del rostro del Furor del grupo Carlos V y el Furor. Leone Leoni, 1550-1553, y acabada por Pompeo Leoni en 1564. (C) Museo del Prado, E-273.

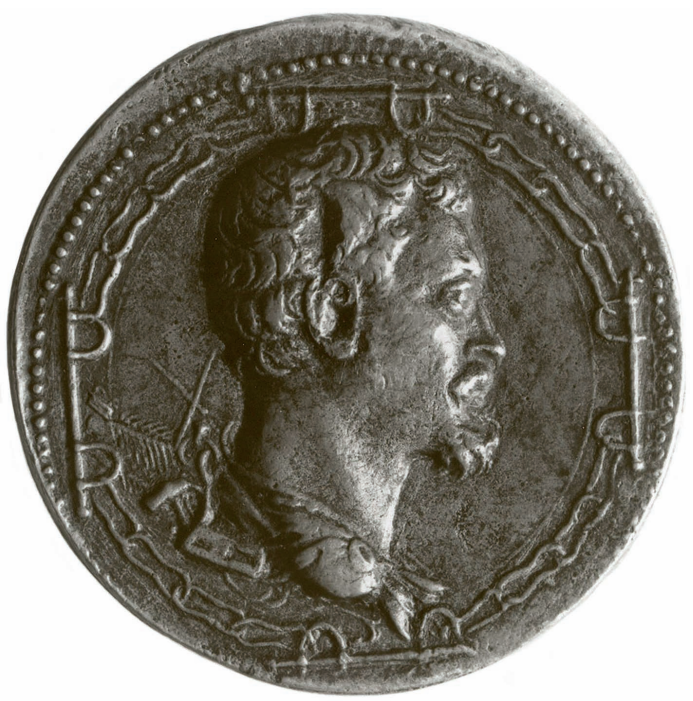

Fig. 2. Autorretrato de Leone Leoni en el reverso de la moneda dedicada a Andrea Doria. (C) Museo del Prado O-982.

artista por agradar con su propia iniciativa, pero también por otras solicitudes, algunas del propio comitente. Así, en enero de 1551 Carlos V le ordenó que acudiese a Augsburgo para que en su presencia hiciera los bustos de su hermano Fernando de Austria, rey de Romanos, y del hijo de éste Maximiliano, rey de Bohemia ${ }^{22}$. Otras parecen estar relacionadas con el obispo de Arras, que acusó a los Leoni de ser lentos en su trabajo y provocó que Leone le enviara una enumeración de obras que había realizado: diez cabezas del natural, treinta medallas de oro y plata, dos estatuas de bronce, que pronto serían tres, varios modelos, bajorrelieves... ${ }^{23}$. Además, en esas fechas su hijo Pompeo por deseo del obispo de Arras viajó a Roma y a Innsbruck.

En 1553 trabajó en las esculturas de mármol encargadas por el emperador, y para las que en lugar de desplazarse a Carrara eligió los mármoles al servicio de éste en la cartuja de Pavía ${ }^{24}$. Su labor no debió parecer suficiente, por lo que

\footnotetext{
${ }^{21}$ Carta del Leon Leoni al obispo de Arras (Milán, 03-01-1556) en Plon, 1887: 116-117 y 377-378.

${ }^{22}$ Plon, 1887: $72-73$ y 363.

${ }^{23}$ Plon, 1887: capítulo V.

${ }^{24}$ Rochinni, 1865: 16 y 33.
} 
el gobernador tuvo que informar a finales de año de lo realmente realizado por Leone Leoni del encargo inicial, y que consistía en cuatro esculturas de bronce y cuatro de mármol, como especificó el propio emperador en carta al gobernador ${ }^{25}$. Éste, aderezándolo con elogios, describió los siguientes trabajos: había fundido cuatro estatuas de bronce; de tamaño natural la del Príncipe, la de la reina María y la de Carlos V, y bajo los pies de ésta, y de tamaño mayor que el natural, el artista añadió el Furor, de la que el gobernador alaba su contorsión y horrible expresión del rostro, que la otorgaban vida. Entre los trabajos de piedra describe el inicio de una estatua de mármol de Carrara de la que surgía con gran parecido el rostro del emperador; un medio cuerpo del mismo material del emperador, acabado; un relieve de la emperatriz y un medio cuerpo del emperador, que también debían ser fundidas. Además, certificaba haber visto otras obras comenzadas. La contestación de Carlos $\mathrm{V}$ al gobernador de Milán mostraba su decepción pues esperaba estuviera más adelantado el encargo, por lo que decidió cancelar la pensión del escultor y entregarle sólo cantidades estrictamente necesarias para la finalización del encargo, del que deseaba no levantase la mano. Finalmente, sobre el ofrecimiento de su estatua ecuestre que quería costear el remitente contestó el emperador, en el mismo tono de hastío frente a promesas y tal vez receloso ante los posibles rumores acerca de su gestión: "haréis lo que os pareciere"26. Ese mismo año la denuncia de malversación de fondos y corrupción hizo que el emperador lo destituyera de su cargo de gobernador, y aunque posteriormente se anuló el proceso, supuso el final del proyecto laudatorio, aunque el inicio de otros que intentaban resarcir su memoria ${ }^{27}$.

El explícito control imperial y la presión económica al suspender su asignación hicieron que Leone Leoni diera prioridad a este asunto. En carta del 14 de agosto de 1555 enviada por él desde Milán al obispo de Arras anunciaba que estaban a punto para su envío hacia España cinco bronces y un busto de mármol del emperador. Recordemos que el encargo eran cuatro bronces, pero que Leone decidió añadir el Furor al retrato de Carlos V con armadura desmontable; además, la escultura de la emperatriz, el busto del emperador (también mármol) y uno de los relieves de bronce. Asimismo, se comprometía a llevar las dos esculturas de la reina María de Hungría. Para la seguridad de las obras se ofreció a ir con ellas junto a muchos de sus alumnos capaces de trabajar el mármol, metal, estuco y cera, y acostumbrados a sus gustos. Respecto al resto de esculturas del encargo, y por lo tanto mármoles, dos grandes y bellos relieves cuadrados casi terminados, una estatua de tamaño natural de la emperatriz, y un bloque desbastado para realizar un busto de la emperatriz (sic?), consideraba que por pesar más podían enviarse desde Génova en el barco que debía llevar hasta Flandes numerosos mármoles destinados a la reina. Finalmente, en la misma carta anunciaba al obispo de Arras que le llevaría dos piedras de tres brazas que consiguió en la mina de Polvaccio, en Carrara, para trabajarlas y dejar recuerdo de él en la casa cuya decoración tanto cuidaba. Finalmente, insistía en su interés en llevar las dos esculturas para la reina y en asentarlas él mismo, pues trabajaría con gusto para la soberana en un proyecto que consideraba propio y que causaría la admiración del propio Miguel Ángel ${ }^{28}$, al que él siempre tuvo en gran consideración. A este respecto, el obispo de Arras le comunicó que la reina María de Hungría por su inminente regreso a España y tras el saqueo del palacio de Binche no deseaba emprender nuevas

\footnotetext{
${ }^{25}$ Carta de Ferrante de Gonzaga al emperador (28-12-1553) transcrita en Plon, 1887: 95-97 y 368-369. Otro elogio del Furor en la carta del 3 de marzo de 1554 de M.A. Patanella a Granvelle en Lettere, 1977: 83. La carta del emperador al gobernador en PLON, 1887: 97-98 y 369-370.

${ }^{26}$ Carta (26-01-1554) en Plon, 1887: 369.

${ }^{27}$ Por ejemplo, la medalla de bronce con su figura y cuyo reverso representaba a Hércules venciendo al León de Nemea y con leyenda latina que exhortaba a no ceder ante el mal, de 1555, y la escultura que encargó su hijo y por el que representó a Ferrante triunfando sobre el vicio y la envidia, de 1562-1564, pero erigida en 1594 por Pompeo Leoni delante del palacio ducal de Guastalla. Rochinni, 1865: 19-21 y 38-40. Butti, 1995.

${ }^{28}$ PLON, 1887: 100-102 y 370-371.
} 
obras, por lo que ordenaba que sus mármoles se guardasen en Cádiz hasta que dispusiera qué quería hacer con ellos. Por este motivo, a la reprimenda del emperador por la tardanza en su encargo, se añadía ahora la del obispo por la dilación en el proyecto de la galería con esculturas que la reina María de Hungría mostró antes de 1550 a Leone para dicho palacio, y que el obispo aconsejaba ahora tuviese preparadas para cuando se le reclamasen ${ }^{29}$.

A finales de 1555, el obispo de Arras desde Bruselas comunicaba a Leone Leoni que el emperador todavía retrasaría unos meses su regreso a España y que deseaba ver las obras, por lo que había escrito al duque de Alba para que se enviaran inmediatamente las que pudieran transportarse por tierra y que el resto se hiciese por mar. Y, con elocuencia le recordaba el obispo al escultor que los príncipes desean ver pronto cumplidos sus deseos, o pierden la ilusión. Ciertamente, el consejo se aplicaba al encargo del emperador, para el que a comienzos de 1556 indicaba Leone que con unos 600 escudos podría finalizarlo en cinco meses, y el de María de Hungría, para el que ya había entregado las dos obras comprometidas, mientras que el resto ya no procedía tras el incendio del palacio de Binche. Leone no gozó del tiempo estimado, pues en el mismo mes de enero fue llamado por el emperador para que acudiese a Bruselas con sus obras y embarcase en Génova las otras, el 11 de febrero todavía seguía en Milán, a buen seguro ocupado en el proceso de embalaje de las obras acabadas e intentando adelantar las que todavía no lo estaban, como finalmente se mandó alguna ante los requerimientos del emperador, pero ya a finales de mes se hallaba en Spira de camino ${ }^{30}$. Como él mismo admitió, coincidiendo con la abdicación de Carlos $\mathrm{V}^{31}$, su imagen mejoró cuando en Bruselas pudo mostrar al rey Felipe II su trabajo. A éste se añadiría una escultura de mármol de Carrara que representaba al mismo monarca y que ya en el mes de marzo llevó su hijo Pompeo ${ }^{32}$, encargado de los desplazamientos de las piezas mientras Leone en Bruselas las ultimaba.

Por otro lado, Pompeo Leoni y parte de los trabajos llegados a Bruselas del taller paterno milanés partieron hacia España con el emperador y sus hermanas, que desembarcaron el 28 de septiembre de 1556. El deseo de éste era que lo acompañase Leone, pero el artista utilizó todos los argumentos e influencias para no abandonar Italia, ofreciendo a su hijo ${ }^{33}$. En septiembre Leone se encontraba en Milán y Pompeo en España, donde fue encausado de luteranismo ante el tribunal de la Inquisición, con pena de un año de reclusión en un convento. Leone en cartas al obispo de Arras manifestó su preocupación por no poder ir a ver a su hijo a España y abrigó el deseo de que volviera $^{34}$. Sin embargo, el rey en enero de 1559 dispuso que Leone fuera a España para entender en algunas obras que le había encomendado ${ }^{35}$. La posibilidad de este viaje hizo que de nuevo ofreciera a su hijo, lo que supuso la interrupción de sus pretensiones, y su ofrecimiento en servicio del monarca español; por ejemplo, en su viaje a Roma de 1560 para besar las manos de Pío IV, que era conocido suyo antes de ser incluso cardenal. El papa le encargó la tumba de su hermano Gian Giacomo Medici, marqués de Marignano, para la catedral de Milán finalizada en 1564, y para cuya traza contó con la colaboración del anciano, admirado y huraño Miguel Ángel. Razón

\footnotetext{
${ }^{29}$ Carta del obispo de Arras a Leon Leoni (Bruselas, 12-10-1555) en Plon, 1887: 105-106 y 372.

${ }^{30}$ RochinNi, 1865: 18 y 34-38. Plon, 1887: $115-121$ y 376-378.

${ }^{31}$ En octubre de 1555 concedió a su hijo Felipe Países Bajos y Franco Condado, y en enero de 1556 España, Cerdeña y Nuevo Mundo.

32 RochinNi, 1865: 19 y 35-36.

${ }^{33}$ En cartas de Leon Leoni, firmadas en Bruselas en junio y agosto de 1556, manifestaba su deseo de volver a su amada Italia y enviar a su hijo a España donde el emperador también quería llevarle para su desesperación. RochINNI, 1865: 19 y 36-38.

${ }^{34}$ Cartas de Leone en noviembre de 1558 y enero de 1559; además cartas sobre este tema entre el emperador y Juan Vázquez en julio de 1558. Plon, 1887: 380-381 y 386-388. Bustamante, 1995.

${ }^{35}$ Plon, 1887: 382.
} 
por la que se ofreció ante el rey para pedirle algún diseño para la tumba del emperador ${ }^{36}$. Una solución que podía mostrar su valía en tierras italianas y una forma de asegurarse un ambicioso proyecto, del que carecía desde la muerte del emperador. Finalmente, se descartó por no compartir el pensamiento de Carlos V y su hijo esas gentilidades de carácter suntuoso.

Además de su prisión Pompeo padeció la movilidad de la corte, y trabajó principalmente en Valladolid. Así, algunas de las obras de la reina María en 1558 se guardaron en el convento de San Agustín, mientras que otras de bronce quedaron en el taller de Pompeo en el convento de San Benito ${ }^{37}$. Finalmente, se estableció en Madrid en 1561. Poco después, Giorgio Vasari expuso cómo gran parte de las obras realizadas por Leone estaban en el palacio real madrileño y en el puerto de Alicante, donde se mandaron para trasladarlas posteriormente hacia Granada donde se encontraba el panteón real ${ }^{38}$. En realidad, en cuanto al destino, no estaba muy mal informado, pues se encontraban en Cartagena.

El emperador recibió las esculturas de bronce, y desde Amberes ordenó al embajador de Génova que enviase las de mármol a Cartagena y advirtiese de su partida a Alberto Clavijo, deán de Cartagena. Las estatuas de mármol en cuatro cajas de madera y un busto desbastado fuera de ellas llegaron en la carraca Centuriona, y las guardó en una estancia de la casa del rey en Cartagena, de lo que el deán informó el 1 de mayo de $1556^{39}$.

Este puerto fue una de las vías de entrada más habituales de productos italianos procedentes, entre otros puertos, de Génova. El armamento lombardo, el mármol de Carrara, etc., llegaban al puerto de Cartagena y los barcos regresaban con el salitre murciano. Para las piezas que exigían un especial cuidado el hombre de confianza fue Alberto Clavijo, deán de Cartagena. Así lo muestra el que su competencia se extendiera a otros puertos; por ejemplo, en 1563 recibió la orden de Felipe II de recibir de Cádiz las numerosas piezas de mármol propiedad de María de Hungría y enviarlas a Aranjuez ${ }^{40}$.

Igualmente, en 1563 Felipe II advertía a Clavijo de la llegada, nuevamente en la nave Centuriona, de nuevas piezas procedentes de Génova con mármoles de Carrara para fuentes que había ordenado hacer en Madrid. Decía:

El comendador Figueroa mi embaxador en Genova me scrive, que habia hecho embarcar en la nave Centuriona ciertas caxas con marmoles de Carrara y otras cosas que yo hago traer de Italia para unas fuentes que he mandado que se hagan en Madrid, las quales vien dirigidas a vos, por si la nave aportasse a esse puerto, y en caso que vaya a Alicante van al Bayle de ally, y porque holgariamos que estas cosas llegasen a Madrid con brevedad y bien tratadas os encargo mucho que si la dicha nave aportare a esse puerto, vos procureis que se descarguen lugo las dichas caxas, que como arriba está dicho embia el embaxador Figueroa y hagais de manera que se lleven a muy buen recaudo, a la villa de Madrid dirigidas a mis officiales que ally entienden en mis obras, que ya ellos estarán prevenidos para recibillas y pagar la costa que se huviere hecho en llevarlas, que en usar en diligencia y en avisarme de como se aurá hecho, me hareis plazer. Dat. ${ }^{41}$

En esa misma década las obras en el alcázar de Madrid y casa del Pardo concentraron numerosos esfuerzos en jardines, en cuya labor jugó un papel importante Juan Antonio Hormano, escultor y

${ }^{36}$ Rochinni, 1865: 21. Plon, 1887: 383-384. Sobre este proyecto véanse los numerosos trabajos de Bustamante, reseñados en la bibliografía. Así como nuevos datos de la correspondencia sobre este proyecto en PÉrEz De Tudela, 2000: 249-266. Sobre su inserción en la proyección de la basílica, así como las propuestas de Guglielmo della Porta para la tumba imperial, véase MARÍAs, 1998.

${ }^{37}$ Estella, 2000: 283-321

38 VASARI, 1568: secondo volumen della Terza Parte, 841.

39 AGS, Estado, legajo 113, exp. 124.

${ }^{40}$ Estella, 2001.

${ }^{41}$ AGS, Estado, legajo 143, exp. 226. Monzón, 26 de septiembre de 1563. 
fontanero de Su Majestad. Para estas tareas se pidió a Juan de Guzmán, vecino de Málaga y probablemente su alcaide, que contratase la compra de distintos tipos de jaspes, así como otras piedras para fuentes rústicas. La cuenta del 25 de mayo de 1569 entre Luis Hurtado veedor de las obras del Alcázar de Madrid y Casa del Pardo y el escultor de Su Majestad Jacome da Trezzo (Trezzo sull'Adda, h. 1515 - Madrid, 1589), formado en Milán y con importante labor como orfebre y medallista, establecía un valor de 490 ducados $^{42}$.

Volviendo a las palabras de Vasari, el carácter aleatorio de muchos envíos hacia los puertos mediterráneos españoles, especialmente los de Alicante y Cartagena, así como la frecuencia de los envíos, pueden justificar el error del biógrafo aretino. Un desliz que sería propio de Leone o de su círculo más cercano, como lo refleja la frase que muestra el deseo de Pompeo de regresar a Milán, y que al menos parece mostrar la obsesión paterna. Recordemos que entonces las obras simplemente se enviaron a Génova para embarcarlas hacia España.

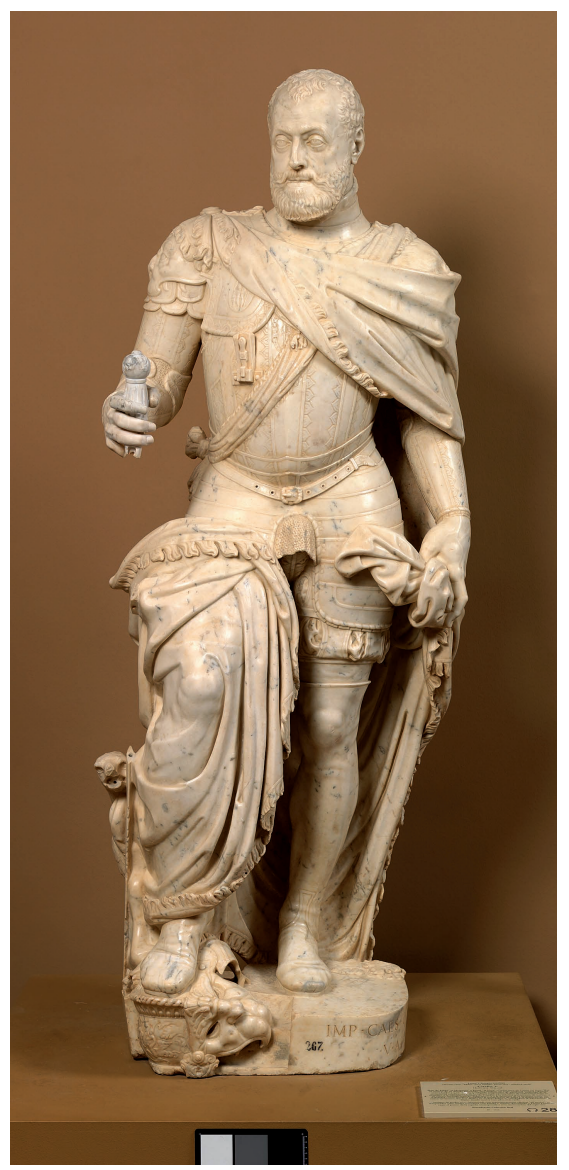

Fig. 4. Carlos V. Leone Leoni, 1553-1556. Mármol, $197 \mathrm{~cm} \mathrm{x} 79 \mathrm{~cm}$ x $44 \mathrm{~cm}-617 \mathrm{~kg}$. (C) Museo del Prado, E-267.

${ }^{42}$ AGS, Dirección General Tesoro, Inv. 24, legajo 565.

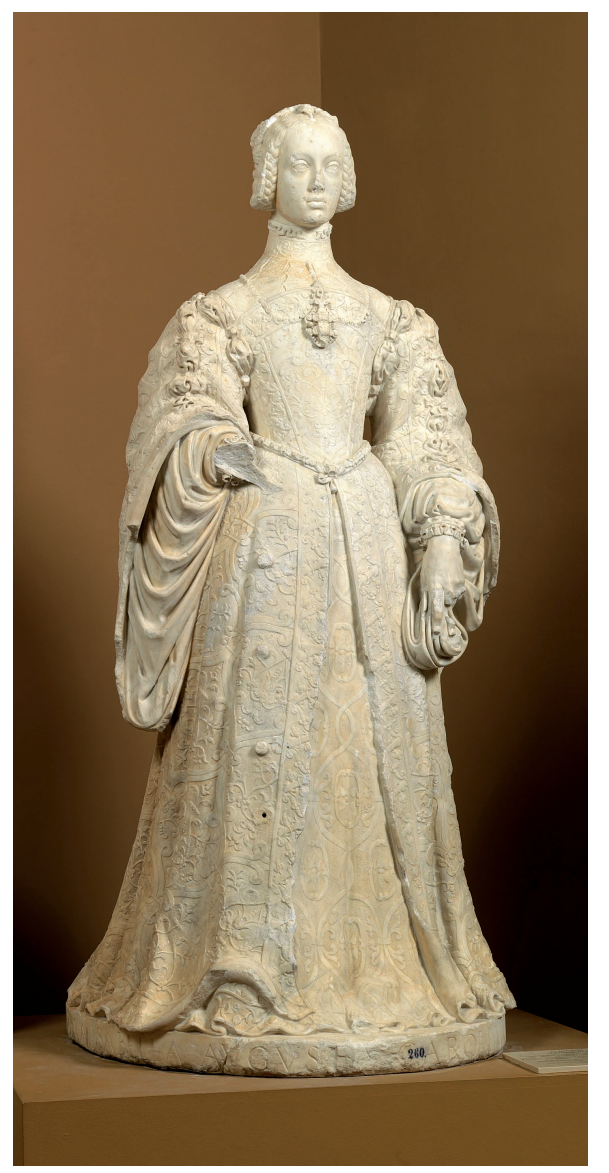

Fig. 5. Isabel de Portugal, Leone Leoni, h. 1555, y finalizada por Pompeo Leoni en 1572. Mármol, $182 \mathrm{~cm}$ x $81 \mathrm{~cm}$ x $114 \mathrm{~cm}-980 \mathrm{~kg}$. (C) Museo del Prado, E-260. 


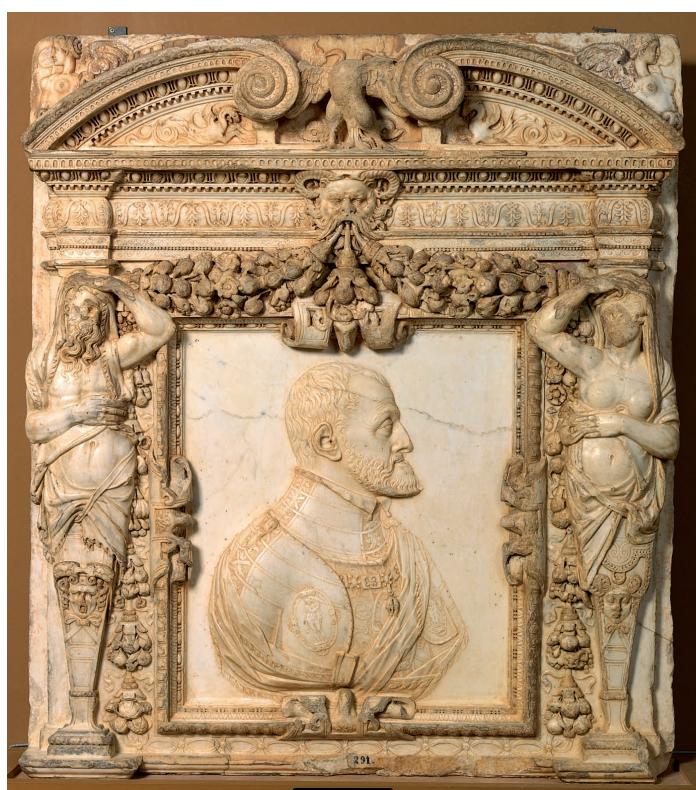

Fig. 6. El emperador Carlos V, Leone Leoni, 15531556. Mármol, $152 \mathrm{~cm} \mathrm{x} 133 \mathrm{~cm} \mathrm{x} 10 \mathrm{~cm}-708 \mathrm{~kg}$. (C) Museo del Prado, E-291.

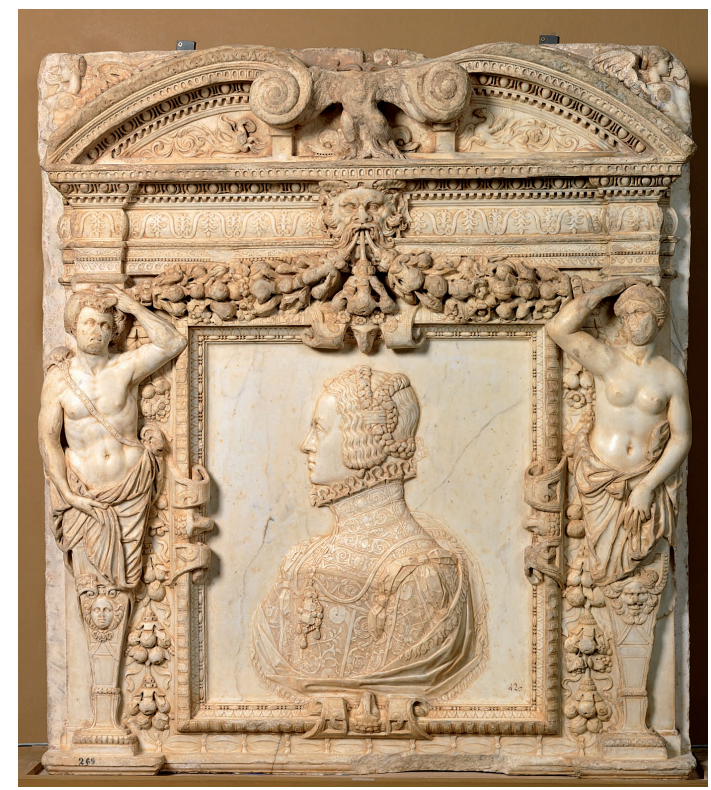

Fig. 7. La emperatriz Isabel, Leone Leoni, 1553 Mármol, $152 \mathrm{~cm} \mathrm{x} 136 \mathrm{~cm} \mathrm{x} 16 \mathrm{~cm}-841 \mathrm{~kg}$. (C) Museo del Prado, E-269.

Por otro lado, la impaciencia mostrada en la carta del rey de 1563 contrasta con el olvido de las obras de mármol llegadas en 1556, y que permanecieron encerradas hasta 1568. Por palabras del rey sabemos que Pompeo condujo las esculturas de bronce y mármol encargadas por el emperador (se citan las de éste, la emperatriz, las reinas María y Leonor, y otras) desde Milán a Flandes y desde allí hasta España con el regreso del emperador y sus hermanas. En Madrid quedaron bajo la custodia del mismo escultor, que siguió trabajando en el encargo y en otros nuevos. Para unificar las cuentas de lo pagado, el 12 de mayo de 1562 Felipe II solicitó al marqués de Pescara, gobernador de Milán, que se sacaran cuentas de lo que se había abonado a los dos escultores a través de la regia cámara de Milán en tiempos de Ferrante Gonzaga ${ }^{43}$.

La contestación se produjo el 27 de julio de $1562^{44}$. Según ésta podemos saber que Leone Leoni, escultor de Su Majestad, recibió del emperador encargos para hacer estatuas de bronce y mármol, que comenzó a cobrar en marzo de 1550. El día 15 recibió 600 escudos y ese mismo día 60 escudos más, que es la cantidad que más regularmente recibe mensualmente, y el último pago, de 793 escudos y 60 sueldos, lo recibió en febrero de 1556 para pagar metal y el transporte de las esculturas desde su taller en Milán a Bruselas y Génova. Los pagos anuales muestran la evolución del encargo: 1.800 escudos en 1550 desde marzo, 1.318 en 1551, 400 en 1552, nada en 1553, 660 en 1554, 200 en 1555 y el citado pago de 793 escudos y 60 sueldos en febrero de 1556 . A estos 5.171 escudos (de a 10 reales y 13 cuartillos cada escudo) pagados por la cámara ducal de Milán, debían sumarse 1.500 escudos pagados por la reina María de Hungría a través de las cuentas de Alemania, y ya en España las esculturas por dos cédulas reales se pagaron 600 escudos. En total, Leone Leoni aretino había recibido 7.140 ducados.

\footnotetext{
${ }^{43}$ PLon, 1887: 386. Y se solicitó que se enviase al secretario real Francisco de Erasso.

44 AGS, Dirección General del Tesoro, Inventario 24, legajo 565.
} 
Por real cédula, firmada por Felipe II en Guadalajara el 29 de agosto de 1563, se estableció que Pompeo Leoni cobraría además de su salario ordinario de $30 \mathrm{du}$ cados mensuales, todo lo que hubieran hecho tanto su padre como él del encargo todavía arrastrado y que suponía la compra de metales y mármol, el pago a oficiales, el transporte... ${ }^{45}$ Por cuenta realizada en Madrid el 9 de octubre de 1567 podemos saber que del encargo inicial los Leoni habían esculpido o fundido en Milán y puesto en toda perfección en la villa de Madrid a través del envío a Bruselas: el grupo de bronce Carlos $\mathrm{V}$ y el Furor, de Carlos V a distinta edad dos bustos, uno en bronce y otro en mármol, de la emperatriz un bajorrelieve y una estatua de bronce, y de María de Hungría un bronce. Mientras que las esculturas de mármol comenzadas o desbastadas y enviadas a Génova se encontraban almacenadas en Cartagena: de los emperadores Carlos e Isabel, dos de tamaño mayor que el natural, y dos bajorrelieves (uno con el rostro del emperador y el otro con el de la emperatriz), y un busto de la reina María de Hungría ${ }^{46}$.

Con la valoración de estas obras el rey ordenó a Melchor de Herrera, tesorero general, que a los 7.140 ducados que los Leoni habían recibido por todas ellas

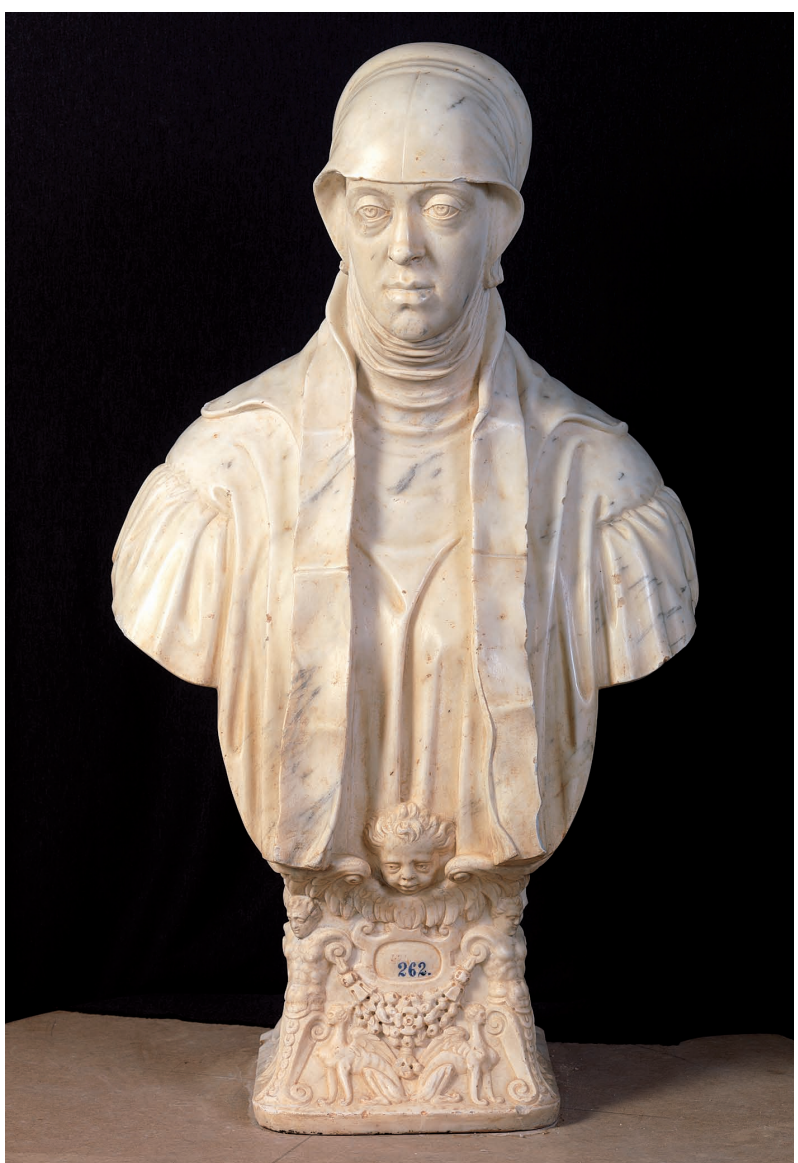

Fig. 8. María de Hungría. Leone Leoni, desbastado h. 1553, y terminado por Pompeo Leoni h. 1570. Mármol, $94 \mathrm{~cm} \mathrm{x}$ $53 \mathrm{~cm}$ x $37 \mathrm{~cm}-112,6 \mathrm{~kg}$. (C) Museo del Prado, E-262. se añadiesen 7.000 más; en concreto, 3.500 ya pagados en $1566,1.500$ que se pagarían en el mismo año de 1567 y 2.000 cuando las obras se dieran por finalizadas. Los plazos, como era habitual, no se cumplieron y los 1.500 ducados se cobraron el 30 de abril de 1568, y se realizaron pagos en 1570 y 1573 , probablemente por el aplazamiento al que pudo obligar su participación en los recibimientos a Ana de Austria en noviembre de 1570. Además, esta estimación excluía el transporte hasta Madrid, que debía realizarse antes de finales de 1568.

El mismo Pompeo Leoni, presente en los encargos del emperador en 1549 y su envío en 1556, fue comisionado para gestionar el traslado de estas esculturas de mármol a través de Juan de Lugano $^{47}$, gran comerciante de este material en España. Así, por cédula de Su Majestad del 12 de diciembre de 1567 cobró 200 ducados del tesorero Melchor de Herrera, para los gastos que ocasionaría llevar las citadas estatuas.

\footnotetext{
45 Plon, 1887: 422-423.

46 CheCA, 1992: 108, 137-138, 475 y 478. Cita en nota la referencia a AGS, DGT, Inv. 24, legajo 565; AGS, CJH, 404.

${ }^{47}$ La documentación se halla en AGS, Contaduría de Cuentas, primera Época, 1567, n. 36; algunos documentos también en legajo AGS, Contaduría de Cuentas, primera Época, 1572, 35.
} 
Pompeo Leoni, junto a dos de sus criados, salió de la corte con el encargo de comprobar las obras que se hallaban en Cartagena y buscar a Lugano, que finalmente encontró en Valencia. Tanto el pago a Pablo de Orta, andante en la Corte, por el alquiler de dos mulas para dos criados de Pompeo, como por los pagos a Pompeo y sus criados por el viaje, aposento, comida para ellos y sus cabalgaduras y otros gastos, sabemos que el itinerario les ocupó 57 días, y por él el maestro cobró 171 ducados ( 3 ducados al día), y sus criados 7.752 maravedíes (a razón de 2 reales al día).

En la ciudad portuaria Pompeo entró en contacto nuevamente con las obras que tuvieron que finalizar y embalar bajo las presiones imperiales años atrás. Confirmado el estado de las piezas, su misión comprendía buscar carpinteros y herreros para embalarlas correctamente, así como encontrar carros armados y personas hábiles para su conducción. De este modo, organizó las acciones que debían realizarse en el puerto y en el mes de febrero de 1568 Lope de Murcia, carpintero de Cartagena, realizó las cajas de gruesos tablones de madera, por las que cobró 24 ducados (9.000 maravedíes), así como 986 maravedíes gastados en peones que sacasen de los almacenes los bultos y los abriesen; y Andrés de Soto, herrero vecino de Cartagena, cobró 4.500 maravedíes por 32 cantoneras de hierro y 16 aldabones para las arcas - cajas en las que se metieron los bultos.

Finalizadas las gestiones en Cartagena Pompeo Leoni partió hacia Valencia, y en esta ciudad el 20 de marzo de 1568 estableció un acuerdo con Juan de Lugano, marmolista morador de Madrid y presente en Valencia, sobre el traslado de cuatro bultos de mármol desde Cartagena hasta la casa de Leoni en Madrid, con fecha de entrega el 15 de junio, «las quales son la una la figura del emperador nuestro senyor que este en el cielo, y la otra de la emperatriz nuestra senyora, y las otras que son dos quadros grandes de mediorelieve», con lo que la coincidencia de bultos, esculturas y temática no ofrece dudas a la hora de vincularlas con el envío de 1556. Por el desplazamiento se fijó un precio de 200 ducados, entregados en dos mitades, la primera con la firma y la segunda con la entrega, y a cargo de Lugano todos los gastos de carretas y gentes, y con la aceptación por las dos partes de una multa de 50 ducados en caso de incumplimiento. Firmaron como testigos Joan Aguiló, baile general de la ciudad y reino de Valencia y caballero de la orden de Santiago, y Vicente María, ciudadano habitador en Valencia.

Juan de Lugano tenía bienes en Suiza y talleres abiertos en España en Valencia, Alicante, Sevilla, y Madrid, donde reside los últimos años de su vida, así se declara al firmar el acuerdo con Pompeo en 1568 y a su muerte en septiembre del año siguiente. Individualmente o en compañías, por ejemplo con su cuñado Francisco de Abril, también natural de la zona del lago de Lugano, gestionó gran parte de la importación de piezas de mármol embarcadas desde Génova, bien arquitectónicas bien escultóricas, bien talladas bien desbastadas, y su contratos se documentan en Sevilla, Toledo, Torrijos, Madrid, Burgos, Murcia, Orihuela, Alicante, Valencia... ${ }^{48}$. Un éxito muy ligado al control de un material que en este tiempo se consideraba valioso y estratégico, como muestran las Relaciones topográficas ordenadas por Felipe II (1575), puesto que entre los más de cincuenta puntos del cuestionario, el 24 pedía que se especificara "si hay minas de oro, plata, yerro, cobre, plomo, azogue y otros metales y minerales de tinturas y colores, y canteras de jaspes, marmor y otras piedras estimadas"; y el 30 incidía en el uso de materiales básicos de la construcción y su dependencia al solicitar información sobre "la suerte de las casas, $\mathrm{y}$ edificios que se vsan en el pueblo, y de que materiales son, y si los hay en la tierra, o los traen de otra parte" 4 .

\footnotetext{
${ }^{48}$ Marqués De Lozoya, 1957. VVAA, 1987. Gómez-Ferrer, 1998. López Torrijos y Nicolau, 2002. Marías, 2002. Nicolau CASTRO, 2005.

${ }^{49}$ Catalogadas, contadas y agrupadas por el P. M. Míguélez a comienzos del siglo XX, aparecieron los primeros índices en la revista agustiniana La Ciudad de Dios (1914, 1915 y 1925) y, posteriormente, en ZarCo Cuevas, J., 1917 y más recientemente en Alvar Ezquerra, A., et al., 1993-1995, vol. IV.
} 
Juan de Lugano falleció poco tiempo después. Por esta razón, de los últimos 100 ducados a la entrega de los bultos quedaron por pagar 30, que cobró Joan Beringoçio (Beringodo ${ }^{50}$ ), milanés residente en la corte, por poder que le otorgaron Gasparina Corona (o Aprile), viuda de Juan de Lugano, y Florbelina de Lugano, hija y heredera de Juan de Lugano y de Gasparina. También aparece entre las cuentas el pago de 4.500 maravedíes (12 ducados) a Andrés de Lugano y en su nombre al carretero que trajo el medio bulto de la reina María y lo entregó con los otros cuatro.

En cuenta realizada en marzo de 1578 Pompeo demostró en esta empresa unos gastos de 94.394 maravedíes, como ya había cobrado 75.000 que empleó en el contrato con Lugano, se le adeudaban 19.394, que finalmente se le abonaron por cédula de S.M. del 11 de agosto de 1581 a través de Juan Fernández de Espinosa.

Por otro lado, resulta relevante señalar que las piezas se entregaron en la casa madrileña de Pompeo a Diamante, su madre, que está documentada en Madrid desde $1566^{51}$. No hay pruebas por el momento de la presencia de su marido Leone, quien en carta de enero de 1565 afirmaba que debía viajar a España, aunque en julio figura en Milán, y G. Vasari apuntó a un viaje anterior a 1567 , momento en el que escribe ${ }^{52}$ y que coincide con los acuerdos que los Leoni a través de Pompeo alcanzaron con Felipe II por los que cobrarían por lo trabajos ya realizados y su finalización. Al menos, en este tiempo la abundante correspondencia de Leone no lo sitúa en Italia hasta julio de 1565.

Resulta difícil precisar el destino inicial de las piezas encargados por el emperador. La primera vez de la que tenemos noticia nos la proporciona Vasari, con las piezas ya en España, y para las que destacó usos funerarios y palaciegos. Las esculturas encomendadas por el emperador en 1549 tenían una fuerte carga afectiva, y su encargo se hacía desde la corte de Bruselas, muy activa en la configuración de la imagen simbólica de claras connotaciones clásicas y también dinásticas; por ejemplo, las primeras con miras a Italia y las segundas al cortejo funerario familiar que acompañaba la tumba del emperador Maximiliano, abuelo de Carlos V, en Innsbruck, un espacio visitado por Pompeo Leoni.

En un principio las piezas debían enviarse a Flandes. Incluso, cuando se decide que por su peso se embarquen en Génova el destino previsto era éste. La abdicación de Carlos $\mathrm{V}$ y el establecimiento de la residencia en España de Carlos V y sus hermanas hicieron cambiar los planes, y en distintos puertos quedaron almacenadas las obras de María de Hungría y Carlos V. Los encargos marmóreos realizados por el emperador en Bruselas en 1549, trabajados en Milán, enviados por Génova a Cartagena, con llegada en 1556, se hallaban en el taller de Pompeo Leoni en la calle de San Francisco el Grande de Madrid en 1568, donde se unían a los bronces y mármoles que llegaron en 1556 y se terminaron hacia 1564. Esto sucedía justo con el inicio del ambicioso proyecto de El Escorial, una fundación pensada como panteón real que reemplazaba la idea granadina citada por Vasari. Y que también sufrió variaciones, puesto que sólo hacia 1578 se impuso la solución de cenotafios parietales en detrimento de la de túmulo central. Diez años más tarde se pensó en grupos sepulcrales de mármol blanco y negro, y sólo en la última década del siglo en bronce.

Evidentemente hay que descartar una utilidad única de las esculturas. Distintos formatos, distintos materiales, duplicidad en la temática..., a lo que hay que unir cambios en el destino previsto de envío. En su inicio o en su devenir pueden argumentarse criterios de exaltación dinástica al modo de la sala de los reyes en el Alcázar de Segovia, comenzada por Alfonso X y retomada por Enrique IV, o piadosos como se hizo en Innsbruck y finalmente en El Escorial, y otros decorativos, evocadores y simbólicos en jardines y estancias palaciegas...

\footnotetext{
${ }^{50}$ En pagos en Toledo aparece como Juan Burrigoco o Burrigozo, véase NicolaU, 2005.

${ }^{51}$ Estella, 1993: 138-139. Estella, 1997.

${ }^{52}$ VASARI, 1568: secondo volumen della Terza Parte, 840. RonchinI, 1865: 40-41.
} 
Paradójicamente la inversión no se utilizó en momentos de exaltación dinástica. No nos consta que se utilizaran en los grandes recibimientos, como los brindados en 1570 a Ana de Austria, cuarta esposa de Felipe II, y para cuyos arcos de triunfo Pompeo realizó una escultura de mármol del rey, y otras imitando bronce; ni en los realizados en 1599 con motivo de la boda de Felipe III y Margarita de Austria. Felipe II se mostró más volcado en la pintura e indiferente a la escultura, y ello a pesar de los intentos del obispo de Arras. El olvido e incluso el destierro de las esculturas fue una constante hasta el gran proyecto del retablo, custodia y cenotafios de El Escorial ${ }^{53}$. Precisamente su intervención en esta labor le supuso el reconocimiento real. Sabíamos que en 1590 ya Pompeo esperaba merced y gratificación por sus trabajos, como muestra la respuesta de Benavidez del 21 de abril de 1590: "Los quinientos ducados a buena cuenta de sus gajes ordinarios de scultor, me pareze es justo se le den por la mucha necesidad que tiene". Finalmente, la orden real del 1 de junio de 1593 estableció que en recompensa a sus trabajos cobrase, además de los 30 ducados mensuales establecidos desde su llegada a España, otros 50 ducados al mes desde abril de 1592 hasta que finalizase su trabajo en El Escorial, y que en 1600 Felipe III, atendiendo al leal servicio del escultor y su avanzada edad, estableció que los cobrara permanentemente, así como los 7.000 ducados por el valor de los dos grupos funerarios y sitiales ${ }^{54}$. Además, podemos añadir en este proceso de reconocimientos en la última década del siglo, y con claras pretensiones de vincularlo a España, que el rey en consideración a los más de treinta y cuatro años de servicio del escultor y particularmente en la realización de las figuras y demás ornamentos de bronce del retablo, custodia y entierros de la basílica del monasterio de San Lorenzo el Real, que le ocuparon doce años, le concedió una renta como remuneración, recompensa y paga de todo ello, lo que excluía cualquier otra pretensión. Así, el 7 de septiembre de 1592, desde Burgos, el rey firmó carta de privilegio de 500 ducados de juro (187.500 maravedíes) sobre alcabalas (en principio de naipes, pero por estar muy cargadas se hizo sobre las del azúcar de Granada), con facultad de poder vender, cambiar, donar, enajenar y transmitir a su muerte ${ }^{55}$.

En El Escorial culminaba su trayectoria, y aparentemente de nada sirvieron los encargos de bronce y mármol realizados en 1549. No podemos establecer con certeza el uso inicial pensado para las esculturas, y que pudieron sufrir cambios con el traslado de la corte a España, pero este era un factor habitual en la escultura, pues como aleccionó el obispo de Arras a Leone en 1555 por sus incumplimientos ante el emperador y ante María de Hungría, los príncipes desean ver pronto cumplidos sus deseos o pierden la ilusión. Por las propias condiciones de trabajo de la escultura, y de los escultores de más prestigio que atendían numerosos encargos, la escultura brindaba menos oportunidades a la paciencia. Por citar simplemente obras de los Leoni que evidencian mudanzas, es elocuente el devenir de la escultura Carlos V y el Furor, realizada entre 1549 y 1553, y en cuyo lapso Leoni añadió el motivo de la armadura desmontable y la figura del Furor encadenado, y terminada según señala la base en 1564 con firma de los dos Leoni, y que permaneció en el taller de Pompeo hasta su muerte en 1608, traslada entonces a los sótanos del palacio madrileño, en 1633 a Aranjuez y poco después trasladada para exponerla, por fin, en el reservado jardín de San Pablo del palacio del Buen Retiro. Y en este tiempo con una clara evolución de su interpretación iconológica, adaptada a los tiempos, pues la figura del Furor, como se reconoce en vida de Pompeo, pasa a ser el Turco en el inventario realizado a su muerte en 1608, y la Herejía en palabras de Vicente Carducho de 1633.

\footnotetext{
${ }^{53}$ Morán, 1994. Pérez De Tudela, 2000. Sobre la amplia bibliografía que trata la obra del retablo y cenotafios de El Escorial véase Plon, 1887. García, 1946. Martín, 1951-1952. Gómez, 1963. Bustamante, 1998; 1993, 1994, $1995-$ 1996, 1997-1998, 1999.

${ }_{54}^{54}$ Noticias que se aportan a través de la reclamación de deudas, véase Plon, 1887: 417-419 y 421-427.

${ }_{55}$ AGS, Contaduría de Mercedes, 480, expediente 1. El documento se encuentra en muy mal estado y la lectura se hace difícil en algunas partes. Los pagos comprenden desde abril de 1592, y para quitar el juro se establece una relación de 14.000 maravedíes el millar.
} 
Por su parte, de las piezas en mármol encargadas por Carlos V en 1549, llegadas a Cartagena en 1556 y trasladadas a Madrid en 1568 podemos decir prácticamente lo mismo. Salvo el busto de María de Hungría, las cuatro restantes aparecen en los inventarios de 1588 y 1608 en el taller de Pompeo Leoni. Encargadas en 1549, los bultos poco aportaban entonces respecto a las de bronce ya conocidas (figs. 4 y 5). Mayor novedad suponía los relieves del emperador y la emperatriz de rica decoración escultórica y arquitectónica ${ }^{56}$, pero ya poco acordes con el clasicismo desornamentado creciente. La de Carlos V (E-267) en el siglo XVIII pasó del palacio real de Madrid a la Academia de Bellas Artes de San Fernando y en 1829 al Prado; la de su esposa Isabel (E-260) se envió al jardín de los Reinos en el palacio del Buen Retiro; los relieves de Carlos V (E-291) e Isabel (E-269) en tiempos de Felipe IV se enviaron a Aranjuez y en 1868 ingresaron en el Prado (figs. 6 y 7); y del busto de María de Hungría (E-262) nada se sabe de su recorrido hasta su llegada al citado museo ${ }^{57}$. Este busto, de dimensiones y pedestal de decoración renacentista similar al del emperador (E-264), ya fue citado por Diego de Villalta en la casa de Pompeo hacia 1590.

Esta dilación en los proyectos y mudanza también se aprecia fuera de España en obras de los Leoni. Por ejemplo, resulta elocuente el caso del grupo de Ferrante triunfando sobre el vicio y la envidia, realizada por Leone hacia 1560-1564, pero erigida en 1594 por Pompeo delante del palacio ducal de Guastalla; o la estatua de bronce de Vespasiano Gonzaga, realizada hacia 1574-1577, erigida en la plaza central de Sabbioneta en 1588 y después transferida al mausoleo de la Incoronata ${ }^{58}$.

En los encargos imperiales de 1549 subyace la idea de eternizar la memoria de los seres queridos, como se aprecia en la insistencia en verlas (en ocasiones a modo de despedida) que manifestó en varias ocasiones Carlos $\mathrm{V}^{59}$, pero también el deseo de incorporar la propia imagen a las generaciones venideras, como sucedió cuando sus sucesores necesitaron legitimarse en las raíces de su mayor poder. Además, se convertían en modelos tridimensionales que fijaban una iconografía para los momentos en los que la memoria se diluyera. Las esculturas realizadas por Leone en vida del emperador eran los testimonios más indicados y sin intermediarios, mientras que el de la emperatriz presentaba las mismas virtudes, aunque tuviera su origen en obras pictóricas, que a buen seguro el propio emperador comentaría con el fin de mejorarlos cuando se los mostró en Bruselas.

En la escultura era frecuente la pretensión de eternidad. Así lo defendían los escultores en los tradicionales ejercicios de comparación entre las artes, como lo manifestó en su correspondencia Leone Leoni ${ }^{60}$, y también lo evidenciaban las colecciones de antigüedades, de originales o copias de las que la pintura era huérfana, como testimoniaban y servían para su propio prestigio y el de su oficio artístico las casas de los Leoni en Milán y Madrid.

La duplicidad de materiales con la misma temática permite diferentes destinos, así como la comparación de resultados que faciliten una elección, e incluso ahonda en el afán de pervivencia. La pintura sirve en ocasiones de base al retrato en escultura, que tiene una interpretación en bronce y mármol, que permite la comparación del resultado más deseado, pero también supone una posibilidad de perpetuar, pues la riqueza del material a lo largo de la historia mostraba la propia destrucción del mismo.

\footnotetext{
${ }^{56}$ Aunque también defendió su llegada desde Flandes, resulta interesante la interpretación de las hermas-cariátides como representaciones de las estaciones en CASTRILLON, 1968, Lima: 11. Flanquean al emperador el invierno como viejo cubriéndose y el otoño como mujer madura, y a la emperatriz el verano y la primavera, ambos de aspecto juvenil tal y como murió ella para convulsión de la sociedad de la época.

${ }^{57}$ Sobre el devenir de estas piezas y la fortuna crítica de los Leoni véase Estella, 1994. Coppel, 1998.

58 Sobre la fortuna de estas obras véase Mezzatesta, 1980. Marías, 1995: 97-103. Butti, 1995: 61-67. Barbieri, 1995: 75-77.

${ }^{59}$ Este criterio se muestra claramente por la decisión del emperador de llevar para su contemplación, y no exposición, tanto en Bruselas antes de partir hacia España, como en su retiro de Yuste, en este caso del grupo Carlos V y el Furor.

${ }^{60}$ Ronchini, 1865. Plon, 1887: 24-25.
} 


\section{BIBLIOGRAFÍA}

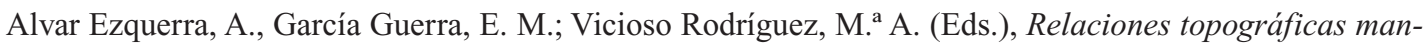
dadas hacer por Felipe II. Madrid, CSIC, 1993-1995, vol. IV.

Barbieri, Franco, "Leone Leoni, Vicenzo Scamozzi e Sabbioneta", Gatti Perer, Maria Luisa (Ed.), Leone Leoni tra Lombardia e Spagna. Milano, Istituto per la storia dell'arte lombarda, 1995, pp. 75-77.

Broucher, Bruce, "Leone Leoni and Primaticcio's Moulds of Antique Sculpture", The Burlington Magazine. 1981, CXXIII, 934, pp. 23-26.

Butti, Attilia Lanza, "Leone Leoni e Ferrante Primo Gonzaga", Gatti Perer, Maria Luisa (Ed.), Leone Leoni tra Lombardia e Spagna. Milano, Istituto per la storia dell'arte lombarda, 1995, pp. 61-67.

Bustamante García, Agustín, "El Santo Oficio de Valladolid y los artistas", Boletín del Seminario de Estudios de Arte y Arqueología. 61, 1995, pp. 455-466.

Bustamante García, Agustín, "Las estatuas de bronce del Escorial: Datos para su historia" (I a V), Anuario del Departamento de Historia y Teoría del Arte, no 5, 6, 7-8, 9-10, 11, 1993, 1994, 1995-1996, $1997-$ 1998, 1999; pp. 41-58, 159-178, 69-86, 153-168 у 129-144.

Bustamante García, Agustín, La Octava Maravilla del Mundo (Estudio histórico sobre El Escorial de Felipe II). Madrid, Alpuerto, 1994.

Bustamante García, Agustín, “Las tumbas reales del Escorial”, Felipe II y el arte de su tiempo, Madrid, 1998, pp. 55-78.

Cabrera de Córdoba, Luis, Felipe II, Rey de España. Madrid, 1619.

Camón Aznar, José, Rejería española del siglo XVI, "Summa Artis", vol. XVIII, 1961.

Castrillon Vizcarra, Alfonso, El arte de Leone Leoni. Extracto de tesis, Lima, 1968.

Checa, Fernando, Felipe II mecenas de las artes, Madrid, Nerea, 1992.

Conti, Paola Barbara, "Vita milanese di Leone Leoni da documenti inediti", Gatti Perer, Maria Luisa (Ed.), Leone Leoni tra Lombardia e Spagna, Milano, Istituto per la storia dell'arte lombarda, 1995, pp. 39-44.

Coppel Aréizaga, Rosario, Catálogo de la escultura de época moderna. Museo del Prado. Siglos XVI-XVIII, Madrid, Museo del Prado, 1998.

Edelstein, Bruce L., "Leone Leoni, Benvenuto Cellini and Francesco Vinta, a Medici Agent in Milan", The Sculpture Journal, vol. 4, 2000, pp. 35-45.

Estella, Margarita, “Algo más sobre Pompeyo Leoni”, Archivo Español de Arte, 262, 1993, pp. 133-149.

Estella, Margarita, "Los Leoni, escultores entre Italia y España”, Los Leoni (1509-1608). Escultores del Renacimiento italiano al servicio de la corte de España. Madrid, Museo del Prado, 1994, pp. 29-62.

Estella, Margarita, "La mujer y el arte en los documentos de los siglos XVI y XVII: Los miembros femeninos de la familia Leoni”, VIII Jornadas de Arte. La mujer en el arte español, Madrid, Alpuerto, 1997.

Estella, Margarita M., "El mecenazgo de la reina María de Hungría en el campo de la escultura", Redondo, M.J.; Zalama, M.A. (Coords.), Carlos V y las artes. Promoción artística y familia imperial. Universidad de Valladolid, 2000, pp. 283-321.

Estella, Margarita M., "Las cuentas del tesorero Roger Patié y otros documentos. Esculturas y antigüedades de María de Hungría y los jardines de Aranjuez", Archivo Español de Arte, 295, 2001, pp. 239-255.

García de Wattenberg, Eloísa, "La obra en bronce hecha en Italia para el retablo y tabernáculos de San Lorenzo el Real del Escorial”, Seminario de Estudios de Arte y Arqueología. XII, 1946, pp. 127-145.

Gómez-Ferrer, Mercedes, "El taller escultórico de Juan de Lugano y Francisco de Aprile en Valencia", El Mediterráneo y el Arte español. Actas del XI Congreso del CEHA, Valencia, Generalitat Valenciana - Ministerio de Educación y Ciencia, Valencia, 1998, pp. 122-129.

Gómez Moreno, María Elena, "La escultura religiosa y funeraria en El Escorial”, Arquitectura-Arte. IV Centenario de la Fundación del Monasterio de San Lorenzo del Escorial. Madrid, Patrimonio Nacional, 1963; vol. II, pp. 491-520.

Helmstutler di Dio, Kelley, Leone Leoni and the Status of the Artist at the End of the Renaissance, Ashgate, 2011.

Lettere di artisti italiani ad Antonio Perrenot di Granvelle: Tiziano, Giovan Battista Mantovano, Primaticcio, Giovanni Paolo Poggini, ed altri. Madrid, Istituto Italiano di Cultura, 1977.

López Torrijos, Rosa; Nicolau Castro, Juan, 'La familia Cárdenas, Juan de Lugano y los encargos de escultura genovesa en el siglo XVI', Boletín del Seminario de Estudios de Arte y Arqueología, LXVIII, 2002, pp. 169-190. 
Marques, Luiz, "Una paradoja sobre las relaciones entre Italia y España en el Renacimiento y la hipótesis de un modelo español”, Redondo Cantera, María José (Coord.), El modelo italiano en las artes plásticas de la Península Ibérica durante el Renacimiento, Universidad de Valladolid, 2004, pp. 77-97.

Marías, Fernando, "Diego de Villalta: fortuna dell'Opera dei Leoni nella Spagna del Cinquecento", Gatti Perer, Maria Luisa (Ed.), Leone Leoni tra Lombardia e Spagna, Milano, Istituto per la storia dell'arte lombarda, 1995, pp. 97-103.

Marías, Fernando, "La iglesia de El Escorial: de templo a basílica", Felipe II y el arte de su tiempo, Madrid, Fundación Argentaria, 1998, pp. 29-53.

Marías, Fernando, "La magnificenza del marmo, la scultura genovese e l'architettura spagnola (secoli XVXVI)", Bocardo, Piero; Colomer, José Luis; Di Fabio, Clario (Dirs.), Genova e la Spagna. Opere, artisti, comittenti, collezionisti. Milán, Silvana Editoriale, 2002, pp. 57-71.

Marqués de Lozoya, Escultura de Carrara en España, Madrid, 1957.

Martín González, Juan José, "Sobre la intervención de Leone Leoni en el retablo del Escorial”, Boletín del Seminario de Estudios de Arte y Arqueología. 18, 1951-1952, pp. 126-127.

Mezzatesta, Michael Philip, Imperial themes in the sculpture of Leone Leoni, New York University, 1980.

Morán Turina, Miguel, "Sobre el gusto por la escultura en la corte de Carlos V y Felipe II", Los Leoni (15091608). Escultores del Renacimiento italiano al servicio de la corte de España. Madrid, Museo del Prado, 1994, pp. 17-28.

Nebbia, Ugo, La casa degli Omenoni in Milano, Ceschina, 1963.

Nicolau Castro, Juan, "La actividad de Juan de Lugano y otros genoveses en Toledo", Boletín del Seminario de Estudios de Arte y Arqueología, LXXI, 2005, pp. 99-121.

Pérez de Tudela, Almudena, "Algunas notas sobre el gusto de Felipe II por la escultura en su juventud a la luz de nuevas cartas entre el obispo de Arrás y Leone Leoni”, Archivo Español de Arte. 291, 2000, pp. 249-266.

Plon, Eugène, Les maitres italiens au service de la maison d'Autriche. Leone Leoni, sculpteur de CharlesQuint et Pompeo Leoni, sculpteur de Philippe II, Paris, E. Plon, Nourrit et cie, 1887.

Proske, Beatrice Gilman, Pompeo Leoni. Work in marble and alabaster in relation to Spanish Sculpture, New York, Hispanic Society of America, 1956.

Ronchini, Amadio, "Leone Leoni d'Arezzo", Atti e memorie delle regie deputazioni di storia patria per le province modenesi e parmensi, 1865, vol. III, pp. 9-41.

Rossi, Marco, "La casa de Leone Leoni a Milano", Gatti Perer, Maria Luisa (Ed.), Leone Leoni tra Lombardia e Spagna, Milano, Istituto per la storia dell'arte lombarda, 1995, pp. 21-30.

Sanchez Canton, F. J., Fuentes literarias para la historia del arte español, Madrid, Imprenta clásica española, 1923.

Sigüenza, Fray José de, Fundación del monasterio de El Escorial. Madrid, 1605.

Vasari, Giorgio, Le vite de' piu eccellenti pittori scultori e architettori, Fiorenza, Apresso i Giunti, 1568.

VVAA, La scultura a Genova e in Liguria. Dalle origini al cinquecento. Genova, 1987.

Zarco Cuevas, J., Catálogo de los Códices Españoles de la Biblioteca de El Escorial. I. Relaciones Históricas (Madrid, 1917).

Fecha de recepción: 3-VI-2012

Fecha de aceptación: 18-VII-2012

Arch. esp. arte, LXXXVI, 342, ABRIL-JUNIO 2013, 87-106, ISSN: 0004-0428 